\title{
Antibiotic Dispensing Practice by Medicine Sellers in Dhaka City-A Cross-Sectional Study
}

\author{
Nazrina $S^{1}$, Rahman $\mathrm{MS}^{2}$, Naznin $\mathrm{R}^{3}$
}

\begin{abstract}
Dispensing antibiotics without prescription is a potential source of inappropriate use. Improvement of antibiotic use is very important in developing countries like Bangladesh. This cross-sectional observational study was conducted in Dhaka city, Bangladesh among 100 purposively selected medicine shops to observe antibiotic dispensing practices of medicine sellers on request for the treatment of nonspecific Upper Respiratory Tract Infection (URTI). Actual practice was assessed with simulated client visit (SCV) with 2 encounters in each medicine shops (a total of 200 encounters). Later self-stated practice was assessed through in-depth interviews with medicine sellers using a digital voice recorder. A total of 42 medicine sellers (42\%) interviewed that they would have recommended antibiotics in response to a presentation of nonspecific URTI. In actual practice, antibiotics were dispensed in 108(54\%) simulated visits. Total 5 drugs (tab ciprofloxacin, tab azithromycin, cap amoxicillin, cap cephradine, tab levofloxacin) was suggested by medicine sellers. Tab ciprofloxacin is the most preferable dispensed drug by medicine sellers in both actual and stated practices which were $73.15 \%$ (79/108 SCV) and 40.48 \%( $17 / 42$ medicine sellers) respectively. The most frequent question was "duration of disease" which was asked by medicine sellers in $76 \%$ (152/200) SCV. None of the medicine sellers asked about allergic history. Antibiotics were dispensed by medicine sellers in Dhaka city without prescriptions and appropriate indications.
\end{abstract}

CBMJ 2020 January: vol. 09 no. 01 P: 11-18

Key words: Dispensing practice, Medicine sellers, Antibiotics, Nonspecific upper respiratory tract infection

\section{Introduction}

In many developing countries including

Bangladesh, the use of antimicrobial drugs for treating people is unregulated. Antibiotics can be purchased without a prescription in medicine shops.1 Moreover Untrained medicine sellers dispense antibiotics, offer alternative antibiotics when the prescribed drugs are out of stock, or refill prescriptions without consulting the prescriber.2,3 Unqualified medicine sellers and unregulated dispensing of antibiotics can lead to a higher incidence of inappropriate use and greater levels of drug resistance.4 Mortality and morbidity from infectious diseases due to antibiotic resistance are increasing day by day all over the world.5 So assessing and improving the dispensing practices of medicine sellers is of great importance for the health of the population. A very few studies have been carried out on dispensing practices by the medicine sellers in our country. Consequently, there is a substantial gap in knowledge around the dispensing behaviors of medicine sellers for antibiotics. Considering the above facts, the present study was designed to observe the dispensing practices of antibiotics by the medicine sellers when the customer approached for treatment of nonspecific upper respiratory tract infection without prescription in Dhaka city.

1. Lt. Col. Sayeda Nazrina, Associate Professor, Department of Pharmacology, AFMC, Dhaka Cantonment.

2. Prof. Dr. Md. Sayedur Rahman, Professor and Chairman, Department of Pharmacology, Bangabandhu Sheikh Mujib Medical University Shahbag, Dhaka

3. Dr. Rubiat Naznin, Assistant Professor, Department of Physiology, Community Based Medical College, Bangladesh, Mymensingh.

Address of correspondence:

Email: shanindigoblue@yahoo.com Mobile: 01711353729 


\section{Materials and Methods}

This cross-sectional observational study was conducted in Dhaka city from Nov 2010 to Feb 2011 on purposively selected 100 medicine shops. Each 25 medicine shops were selected from four traffic division (east, west, north, and south) of Dhaka city. ${ }^{6}$ Small-sized medicine shops $(50$ square feet approximately), one to two medicine sellers per medicine shop were included in the study. Medicine shops within half $\mathrm{km}$ of the tertiary hospital were excluded from the study. A preselected scenario by simulated customer visit $(\mathrm{SCV})^{7}$ was developed to observe the dispensing practices of medicine sellers to see if they suggested antibiotics or not for a patient of nonspecific upper respiratory tract infection. Two volunteers were trained by a professional actor to perform and say the words described in Table-I in a natural and reproducible manner. They bought all recommended drugs and filled in a pre-designed information sheet on the scenario within 15 minutes after the encounter and out of sight of the medicine shop. Two volunteers visited each of 100 medicine shops making a total of $200 \mathrm{SCV}$ s. Only one visit would occur per medicine shop per day. Medicines dispensed in two SCV per medicine shop is termed as 'dispensed consistently'. 'Dispensed occasionally' is termed when medicine sellers dispensed medicines in one SCV per medicine shop. Researchers planned the timing of visits and monitored the progress. After all the simulated customer visits had been completed, face to face in-depth interviews ${ }^{8,9}$ were performed by the principal author using a digital voice recorder which included sociodemographic features of medicine sellers and antibiotic dispensing practices in response to treatment of nonspecific URTI. Verbal informed consent was given by all medicine sellers before the interview. A pilot study was done before starting the main study. The study was approved by the ethical committee of Bangabandhu Sheikh Mujib University (BSMMU).
The results Medical were entered into a computer using Microsoft Excel 2010. Differences between the percentage of actual and stated practices of dispensing different types of antibiotics in response to a presentation of nonspecific URTI were compared. Z-test was done to measure the significance of the difference between them.

\section{Table I:}

Predetermined scenario: 'My brother is suffering from fever, cough and running nose. He took tab napa and tab histacin, but he is not improving. What medicine can be given for rapid cure?'

The simulated customer was 20-25 years of age with casual dressing. He speaks in the local dialect.

If asked by medicine sellers, the following information was to be replied by simulated customers accordingly

His younger brother is suffering from fever, running nose, cough for two days. His brother's age is around 20 years. The temperature rises up to 100 degrees Fahrenheit and comes back to normal after taking medicines, but again it rises. He has a mild headache. But he has no other problem.

\section{Results}

TABLE-II showed the stated and actual dispensing practices of antibiotics in response to a presentation of nonspecific URTI taken by SCV and In-depth interview method respectively in Dhaka city. Forty-two (42\%) medicine sellers stated that they would have suggested antibiotics for the treatment of nonspecific URTI. Among them 36(85.71\%) medicine sellers dispensed antibiotics consistently and 6(14.29\%) medicine sellers sell occasionally in actual practice (Fig-1). Fifty-eight (58\%) medicine sellers stated that they would never sell antibiotics in a presentation of nonspecific URTI (TABLE-II). Fig-2 revealed 40(68.97\%) medicine sellers were consistent with their statements by not dispensing antibiotics consistently which were observed previously 
by SCV. Of the remaining 18 medicine sellers, $12(20.69 \%)$ of them dispensed antibiotics consistently in actual practice previously and $6(10.34 \%)$ of them dispensed antibiotics occasionally.

TABLE-II: Comparison of actual and stated antibiotic dispensing practices by medicine sellers

\begin{tabular}{|c|c|c|}
\hline Variable & $\begin{array}{c}\text { Actual practices } \\
\text { observed by SCV } \\
(\%)\end{array}$ & $\begin{array}{c}\text { Stated practices } \\
\text { observed by in depth } \\
\text { interviews (\%) }\end{array}$ \\
\hline $\begin{array}{c}\text { Suggested } \\
\text { antibiotic }\end{array}$ & $108(54)$ & $42(42)$ \\
\hline Does not \\
suggested \\
antibiotic & $92(46)$ & $58(58)$ \\
\hline Total & $200(100)$ & $100(100)$ \\
\hline
\end{tabular}

${ }^{*} \mathrm{SCV}=$ Simulated Customer Visit

Actual dispensing of antibiotic in presentation of nonspecific URTI $(n=42)$

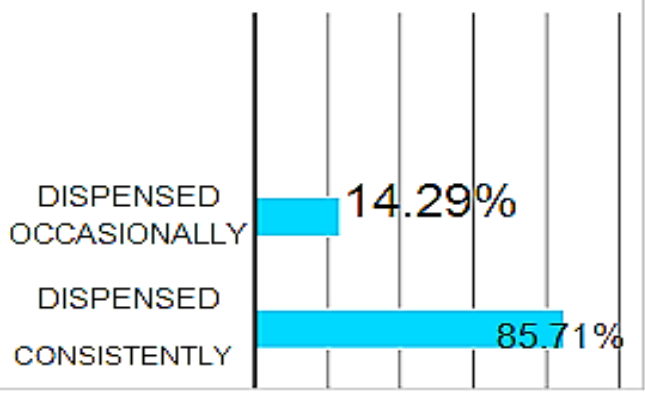

Fig 1: Actual practice by the medicine sellers who stated that they would suggest antibiotics $(n=42)$. 'Dispensed consistently' means dispensed in 2 SCV/medicine shop. 'Dispensed occasionally' means dispensed in $1 \mathrm{SCV} /$ medicine shop.

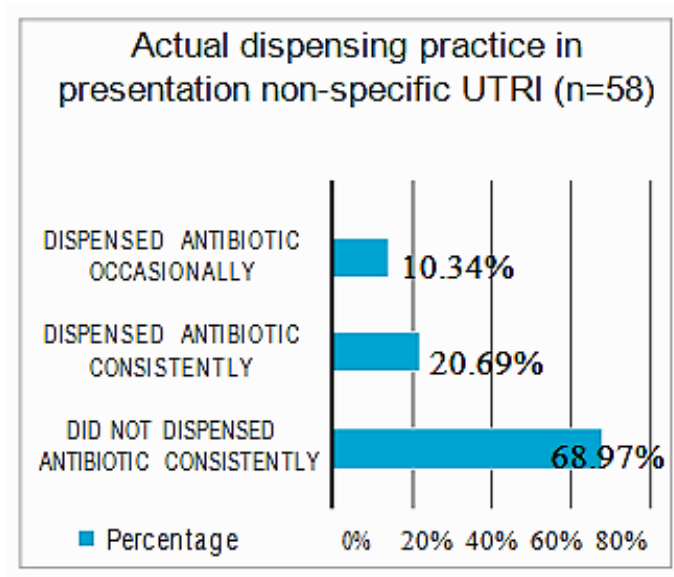

Fig 2: Actual practice by the medicine sellers who replied that they would not suggest antibiotics $(\mathrm{n}=58)$. 'Dispensed consistently' means dispensed in $2 \mathrm{SCV} /$ medicine shop. 'Dispensed occasionally' means dispensed in 1 SCV /medicine shop.

TABLE-III showed antibiotics suggested by medicine sellers in response to a presentation of Nonspecific URTI in actual and stated practices. The percentage of actual dispensing practice (73.15\%) of tab ciprofloxacin is higher than the percentage of stated practice $(40.48 \%)$ which is statistically significant. But in the case of tab azithromycin, cap amoxicillin, cap cephradine, percentages of stated practices are higher than percentages of actual practices which are statistically significant. Tab levofloxacin was suggested by medicine sellers least in both actual $(2.78 \%)$ and stated $(4.76 \%)$ practice and the difference between the practices is statistically insignificant. 
TABLE-III: Antibiotics recommended by medicine sellers in response to a presentation of nonspecific URTI in actual and stated practices

\begin{tabular}{|l|c|l|c|}
\hline $\begin{array}{c}\text { Name of antibiotics } \\
\text { recommended }\end{array}$ & $\begin{array}{c}\text { Actual } \\
\text { practice* }(\%)\end{array}$ & $\begin{array}{c}\text { Stated } \\
\text { practice* } \\
(\%)\end{array}$ & p-value \\
\hline Tab Ciprofloxacin & $79(73.15)$ & $17(40.48)$ & 0.00005 \\
\hline Tab Azithromycin & $22(20.37)$ & $12(28.57)$ & 0.0168 \\
\hline Cap Amoxycillin & $2(1.85)$ & $7(16.67)$ & 0.003 \\
\hline Cap Cephradine & $2(1.85)$ & $4(9.52)$ & 0.0263 \\
\hline Tab Levofloxacin & $3(2.78)$ & $2(4.76)$ & 0.1473 \\
\hline Total & $108(100)$ & $42(100)$ & \\
\hline
\end{tabular}

${ }^{*}$ Actual dispensing practices observed by SCV (2 visits/shop)

**Stated dispensing practices obtained by face to face in-depth interview (1 interview/shop)

TABLE-IV showed the different duration and doses of antibiotics suggested by medicine sellers in actual practice. Tab ciprofloxacin $(500 \mathrm{mg}$ ) twice daily for 5 days was the most popular duration recommended by medicine sellers. Tab ciprofloxacin $(250 \mathrm{mg}$ ) was also suggested by medicine sellers for 7 days and 5 days in $1.26 \%$ and $3.80 \%$ simulated visits respectively. Tab azithromycin was suggested once daily for 3 days, 7 days, 5 days in $8.33 \%, 6.48 \%$, and $4.63 \%$ simulated visit respectively. Medicine sellers suggested tab levofloxacin $(500 \mathrm{mg}$ ) once daily for 7 days $(2.78 \%$ SCV), cap amoxicillin $(250 \mathrm{mg})$ for 5 days $(1.85 \% \mathrm{SCV})$, cap cephradine $(500 \mathrm{mg})$ for 5 days $(1.85 \%$ SCV $)$. One medicine seller suggested tab azithromycin $(500 \mathrm{mg}$ ) for 1 day then $250 \mathrm{mg}$ for the next 4 days.
TABLE-IV: Duration and doses of antibiotics dispensed by medicine sellers to simulated customers $(n=108)$

\begin{tabular}{|l|l|l|}
\hline Name of Antibiotics & $\begin{array}{l}\text { No of } \\
\text { SCV }^{*}\end{array}$ & Percentage \\
\hline Tab Ciprofloxacin & & \\
\hline $500 \mathrm{mg}$ twice daily for 7 days & 25 & 23.15 \\
$500 \mathrm{mg}$ twice daily for 5 days & 38 & 35.18 \\
$500 \mathrm{mg}$ twice daily for 3 days & 12 & 11.11 \\
$250 \mathrm{mg}$ twice daily for 7 days & 1 & 0.92 \\
$250 \mathrm{mg}$ twice daily for 5 days & 3 & 2.78 \\
\hline Tab Azithromycin & & \\
$500 \mathrm{mg}$ twice daily for 7 days & 7 & 6.48 \\
$500 \mathrm{mg}$ once daily for 5 days & 5 & 4.63 \\
$500 \mathrm{mg}$ once daily for 3 days & 9 & 8.33 \\
$500 \mathrm{mg} 1$ st day $500 \mathrm{mg}$, & 1 & 0.92 \\
then 250 mg daily for 5 days & & \\
\hline Tab Levofloxacin & & \\
$500 \mathrm{mg}$ once daily for 7 days & 3 & 2.78 \\
\hline Cap Amoxycillin & & \\
$250 \mathrm{mg}$ thrice daily for 5 days & 2 & 1.85 \\
\hline Cap Cephradine & & \\
$500 \mathrm{mg}$ thrice daily for 5 days & 2 & 1.85 \\
\hline
\end{tabular}

${ }^{*}$ SCV $=$ Simulated Customer Visit

Fig-3 showed medicines other than antibiotics were dispensed by medicine sellers in 30(15\%) SCVs. In 14 (46.67\%) SCV, other medicines were dispensed with antibiotics to simulated customers. The most dispensed drug was tab paracetamol + caffeine which were dispensed in $12(40 \%)$ SCV. Then tab cetirizine was dispensed in $6(20 \%)$ SCVs. Tab desloratadine and paracetamol suppository both were dispensed in $3(10 \%)$ SCVs. Both herbal cough syrup and dextromethorphan $\mathrm{HCl}$ syrup were dispensed in 2(6.67\%) SCVs. Both tab fexofenadine and tab salbutamol was dispensed in $1(3.33 \%)$ SCV. 


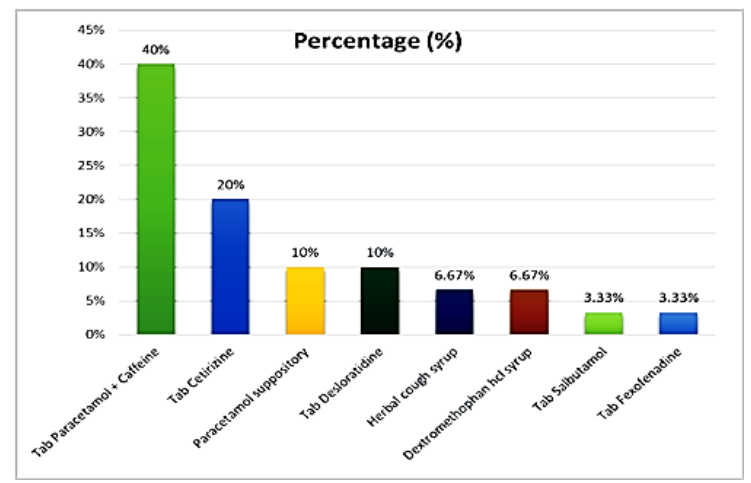

Fig 3: Simulated Customer Visits (SCV) Where other medicines were dispensed by medicine sellers $(n=30)$.

Medicine sellers asked about some information from the stimulated customers during the presentation of nonspecific URTI. Most of the information was asked at the start of the conversation. The most important question for them was the duration of the disease, which was asked by medicine sellers in 76\% (152/200) SCV. The second important information for them was the intensity of the fever which was asked in $42 \%$ ( 84/200) SCV. The patient's age and type of fever were asked in $7.5 \%(15 / 200)$ and $6.5 \%(13 / 200)$ SCV respectively. Seldom asked questions were about headache, cough, and body ache $(1.5 \%$, $1.5 \%, 5 \%$ SCV) (Table V).

TABLE-V: Simulated Customers Visits (SCV) where information was enquired by medicine sellers $(n=200)$

\begin{tabular}{|l|l|l|}
\hline Subject of question & $\begin{array}{l}\text { No. of } \\
\text { SCV }\end{array}$ & Percentage \\
\hline Duration of disease & 152 & 76 \\
\hline Intensity of fever & 84 & 42 \\
\hline Patient's age & 15 & 7.5 \\
\hline $\begin{array}{l}\text { Type of fever } \\
\text { (continuous/intermittent) }\end{array}$ & 13 & 6.5 \\
\hline $\begin{array}{l}\text { Cough } \\
\text { (productive/unproductive) }\end{array}$ & 3 & 1.5 \\
\hline Headache & 3 & 1.5 \\
\hline Body ache & 1 & 0.5 \\
\hline
\end{tabular}

${ }^{*}$ multiple responses
TABLE-VI showed that medicine sellers advised simulated customers during the treatment of nonspecific URTI. The most common advice was to continue previous treatment which was given in $35.5 \%(71 / 200)$ simulated visits. Medicine sellers advised simulated customers to come with patient in 2 simulated visits. The advice was given in $80 \%$ of all the encounters.

TABLE-VI: Simulated Customers Visits (SCV) where advice was given by medicine sellers $(n=200)$

\begin{tabular}{|l|c|c|}
\hline \multicolumn{1}{|c|}{ Advice } & $\begin{array}{c}\text { No. of } \\
\text { SCV }\end{array}$ & percentage \\
\hline Continue previous treatment & 71 & 35.5 \\
\hline Consult with the doctor for treatment & 38 & 19 \\
\hline $\begin{array}{l}\text { Wait for 1-2 days, if disease } \\
\text { persist consult with the doctor }\end{array}$ & 10 & 5 \\
\hline $\begin{array}{l}\text { Wait for 3-4 days, if disease } \\
\text { persist consult with the doctor }\end{array}$ & 10 & 5 \\
\hline $\begin{array}{l}\text { Wait for 5 days, if the disease } \\
\text { persists consult with the doctor }\end{array}$ & 4 & 2 \\
\hline $\begin{array}{l}\text { Wait for 1-2 day, if the disease } \\
\text { persists take the antibiotic }\end{array}$ & 10 & 5 \\
\hline $\begin{array}{l}\text { Wait for 3-4 day, if the disease } \\
\text { persists take the antibiotic }\end{array}$ & 3 & 1.5 \\
\hline Have plenty of water & 3 & 1.5 \\
\hline $\begin{array}{l}\text { Come to medicine seller if } \\
\text { condition not improved }\end{array}$ & 5 & 2.5 \\
\hline $\begin{array}{l}\text { Do not give tab histacin to patient } \\
\text { seeing the patient }\end{array}$ & 4 & 2 \\
\hline No advice given & 40 & 20 \\
\hline
\end{tabular}

In-depth interviews revealed almost all medicine sellers were male (99\%). Most of them (48\%) were between 31-40 years of age. A total of 24 medicine sellers had completed a pharmacy certificate course of 3 months(category $\mathrm{C}$ ) and 3 medicine sellers had completed a 3-year diploma course in pharmacy (category B)(Table VII). 
TABLE-VII: Demographic characteristics of medicine sellers $(n=100)$

\begin{tabular}{|l|c|c|}
\hline \multicolumn{1}{|c|}{ Characteristics } & Frequency & Percentage \\
\hline Gender & 99 & 99 \\
Male & 1 & 1 \\
Female & 2 & 2 \\
\hline Age(years) & 35 & 35 \\
220 & 48 & 48 \\
$20-30$ & 10 & 10 \\
$31-40$ & 5 & 5 \\
$41-50$ & & \\
$>50$ & & \\
\hline Educational status* & & \\
Category C pharmacist & 24 & 24 \\
Category B pharmacist & 3 & 3 \\
Others (Paramedics course, & 32 & 32 \\
LMAF course, etc.) & 43 & 43 \\
No health-related certificates & 43 \\
Do not want to answer & 1 & 1 \\
\hline
\end{tabular}

${ }^{\star}$ Multiple responses $\{3$ medicine sellers had completed both pharmacy certificate and LMAF (Local Medical Assistant and Family Planning Training) course\}

\section{Discussion}

This cross-sectional observational study used a simulated customer visit method for data collection to assess the actual practices of medicine sellers in Dhaka city. In medicine shops usually, no records are kept. To assess actual practices, a researcher may have to wait for a long time for a particular condition. In this situation, this method would give the most reliable result. Hence the purpose of the study was not to deceive medicine sellers but to study their dispensing behavior under realistic settings. ${ }^{7}$

The present study used a simulated illness, nonspecific URTI for which there is no evidence that antibiotics offer clear advantages. ${ }^{10,11}$ However, this study showed that antibiotics were dispensed in the presentation of nonspecific URTI in $54 \%$ of simulated visits. A similar study in Bangalore, India observed, 82 (71.3\%) of the 115 pharmacies dispensed antimicrobials without a prescription in URTI simulation which was more in number. ${ }^{12}$
Later 42 medicine sellers stated they would have recommended antibiotics for the same reason. Several studies have shown that stated practice tends to be better than actual practice. ${ }^{13-15}$

In this study, simulated customers played the role of relatives of the patient which was similar to earlier studies. ${ }^{16-18}$ Only one medicine seller advised simulated customers to come with the patient in both visits in his shop.

Antibiotics recommended to customers in simulated visits were tab ciprofloxacin (73.15\%), tab azithromycin (20.37\%), tab levofloxacin (2.78\%), cap amoxicillin (1.85\%), and cap cephradine $(1.85 \%)$. A similar study in India showed the most common antimicrobial drug dispensed was amoxicillin (51.2\%), followed by azithromycin and ciprofloxacin (12.2\% each). ${ }^{12} \mathrm{~A}$ Greek study in 2001 also revealed most of the pharmacists suggested amoxicillin in the treatment of acute rhinosinusitis. ${ }^{17}$ Another study in Saudi Arabia observed that amoxicillin/ clavulanate was the most commonly dispensed antibiotic in cases of sore throat. ${ }^{18}$

Later among 42 medicine sellers, $17(40.48 \%)$ of them stated that they would like to recommend tab ciprofloxacin in this type of problem. Other suggested antibiotics are tab azithromycin (28.57\%), tab levofloxacin (4.76\%), cap amoxicillin $(16.67 \%)$, and cap cephradine $(9.52 \%)$. There is a sizable difference between actual and stated practices of tab ciprofloxacin. However, in both practices, it is the most preferable dispensed drug among medicine sellers. There is a popular conception that ciprofloxacin can cover almost any disease. Furthermore, the recommendation of drugs can be frequently driven by financial profit and not by rational therapeutic choice and undeniably antibiotics are more profitable than other medicines. ${ }^{19}$ 
In the present study, all medicine sellers instructed orally about dose, duration, and frequency of antibiotic consumption during selling antibiotics to simulated customers. A often to take the antibiotic and $9(37.5 \%)$ pharmacists explained how long the antibiotic should be taken. ${ }^{20}$ Another study in India showed more numbers of medicine sellers (69.5\%) had given instructions on duration and frequency of antibiotic consumption. ${ }^{21}$

In the present study, other medicines were also sold by medicine sellers in 30 simulated visits. A similar study in India observed a small proportion of medicine sellers (30\%) had given nonpharmacological advice (steam inhalation) to simulated customers to reduce symptoms of similar disease. $^{21}$

The present study showed medicine sellers never asked questions regarding the history of drug allergy. The result is comparable to the studies observed in Bangalore, India, and Riyadh, Saudi Arabia. $^{12,18}$ Another Indian study by Jaganathan M et al observed that history of drug allergy was enquired by 7 (15.2\%) medicine sellers only. ${ }^{21}$ Llor and Cots in their study showed query was slightly higher (33.3\%) in similar illness. ${ }^{20}$

The present study showed only 27 medicine sellers were registered pharmacists. According to the Drugs (Control) Ordinance 1982, section (viii), no person being a retailer, is allowed to sell anydrug without the personal supervision of a pharmacist registered in any Register of the Pharmacy Council of Bangladesh. ${ }^{22}$ In our country, most of the time the drugs are dispensed without the direct supervision of any registered pharmacist.

\section{Conclusion}

Dispensing pattern of antibiotics by medicine sellers in Dhaka city is inappropriate. Inappropriate antibiotic dispensing was confirmed in this study by dispensing antibiotics in response to a presentation of nonspecific URTI where antibiotic was not required. Implementation of educational intervention, legislation can improve the dispensing practices of medicine sellers.

\section{Acknowledgements}

We acknowledge Shamol Mawla, an established professional actor, who gave his valuable time and suggestion for the training of the actors. We would also like to thank Khandoker Abdul Zamil, Raisul Islam who volunteered to act as simulated customers.

\section{Financial Support}

Armed Force Medical Institute (AFMI) thesis /dissertation fund and partly by the principal researcher herself.

\section{References:}

1. Hart CA, Kariuki S. Antimicrobial resistance in developing countries. BMJ.1998; 317: 647-650.

2. Kafle $K$, Chinyanganya $F$, Suryawati $S$. Role of Dispensers in Promoting Rational Drug Use. Session Guides. Promoting Rational Drug Use: Course Materials. World Health Organization. 2000.

3. Okeke IN, Adbayo L, Edelman R. Socioeconomic and behavioral factors leading to acquire bacterial resistance to antibiotics in developing countries. Emerg Infect Dis. 1999; 5: 18-27.

4. World Health Organization. The World Drug Situation, Geneva. World Health Organization. 1988.

5. Ventola CL. The antibiotic resistance crisis: part 1: causes and threats. Pharmacy and therapeutics. 2015 Apr;40(4):277.

6. Dhaka Metropolitan Police. Traffic Division. Retrieved June 29, 2010 from http://www.dmp.gov.bd/static/traffic.php

7. Hardon A, Hodgkin C, Fresle D. How to investigate the use of medicines by consumers. World Health Organization and University of Amsterdam; 2004. WHO/EDM/PAR/2004.2.

8. International network for rational use of drugs. How to use applied qualitative methods to design drug use interventions. International Network for Rational Use of Drugs; 1996. 
9. Boyce C, Neale P. Conducting in-depth interviews: A guide for designing and conducting in-depth interviews for evaluation input. Path finder international 2006

10. Rubin MA, Gonzales R, Sande MA. Infections of the upper respiratory tract. In Kasper DL, Braunwald E, Fauci AS, Hauser SL, Longo DL, Jameson JL (eds). Harrison's Principles of Internal Medicine. 16th ed. McGraw-Hill:New York. 2005; p. 185.

11. Gonzales R, Bartlett JG, Besser RE, Hickner JM, Hoffman JR, Sande MA; Centers for disease control and prevention. Principles of appropriate antibiotic use for treatment of nonspecific upper respiratory tract infections in adults: background.Ann Emerg Med. 2001; 37: 698702.

12. Shet $A$, Sundaresan $S$, Forsberg BC. Pharmacybased dispensing of antimicrobial agents without prescription in India: appropriateness and cost burden in the private sector. Antimicrobial resistance and infection control. 2015 Dec;4(1):1-7.

13. Ross-Degnan D, Soumerai SB, Goel PK et al. The impact of face-to-face educational outreach on diarrhoea treatment in pharmacies. Health Policy Plan 1996; 11. 308-318.

14. Chalker J, Ratanawijtrasin S, Chuc NT, Petzold M, Tomson G. Effectiveness of a multi-component intervention on dispensing practices at private pharmacies in Vietnam and Thailand--a randomized controlled trial. Soc Sci Med. 2005; 60: 131-141.

15. Larsson M, Tomson G, Binh NT, Chuc NTK, Falkenberg $T$. Private pharmacy staff in Hanoi dispensing steroids - theory and practice. Pharmacy Practice 2006; 4: 60-67.

16. Chuc NT, Tomson G. "Doi moi" and private pharmacies: A case study on dispensing and financial issues in Hanoi, Vietnam. Eur J Clin Pharmacol. 1999; 55: 325-332.

17. Contopoulos-loannidis DG, Koliofoti ID, Koutroumpa IC, Giannakakis IA, loannidis JP. Pathways for inappropriate dispensing of antibiotics for rhinosinusitis: A randomized trial. Clin Infect Dis. 2001; 33: 76-82.
18. Abdulhak AA, Al Tannir MA, Almansor MA, Almohaya MS, Onazi AS, Marei MA, Aldossary OF, Obeidat SA, Obeidat MA, Riaz MS, Tleyjeh IM. Non prescribed sale of antibiotics in Riyadh, Saudi Arabia: a cross sectional study. BMC public health. 2011 Dec;11(1):1-5.

19. Saha S, Hossain MT. Evaluation of medicines dispensing pattern of private pharmacies in Rajshahi, Bangladesh. BMC health services research. 2017 Dec;17(1):1-8.

20. Llor C, Cots JM. The sale of antibiotics without prescription in pharmacies in Catalonia, Spain. Clinical Infectious Diseases. 2009;48(10):1345-9.

21. Jaganathan $M$, Vallish $B N$, Mayathevar $B$, Mahato RK. Non-prescription sale of antibiotics in pharmacies across Puducherry, India. Int. J. Basic Clin. Pharmacol. 2016:5:2403-6.

22. Drug (control) Ordinance 1982, Bangladesh Gazette, Extraordinary, dated 12th June 1982. No 354 - pub. Government of the People's Republic of Bangladesh. Dhaka, Bangladesh. 